\title{
Determinants of Antenatal Health Care Utilization in Egypt (2000-2014) Using Binary and Count Outcomes
}

\author{
Hassan H. M. Zaky¹, Dina M. Armanious², Mohamed Ali Hussein² \\ ${ }^{1}$ Department of Psychology, School of Humanities and Social Sciences, and Social Research Center of the American University in \\ Cairo, Cairo, Egypt \\ ${ }^{2}$ Department of Statistics, Faculty of Economics and Political Science, Cairo University, Cairo, Egypt \\ ${ }^{3}$ Faculty of Commerce, South Valley University, Qena, Egypt \\ Email: hzaky@aucegypt.edu,dinamagdya@hotmail.com,m3ali83@yahoo.com
}

How to cite this paper: Zaky, H.H.M., Armanious, D.M. and Hussein, M.A. (2019) Determinants of Antenatal Health Care Utilization in Egypt (2000-2014) Using Binary and Count Outcomes. Health, 11, 25-39.

https://doi.org/10.4236/health.2019.111004

Received: December 17, 2018

Accepted: January 8, 2019

Published: January 11, 2019

Copyright (c) 2019 by author(s) and Scientific Research Publishing Inc. This work is licensed under the Creative Commons Attribution International License (CC BY 4.0).

http://creativecommons.org/licenses/by/4.0/

\begin{abstract}
Aim: This study seeks to investigate the factors determining the utilization of antenatal care services, the frequency of that use, and the timing of receiving antenatal care among Egyptian women utilizing a national representative data from Egypt Demographic and Health Surveys (EDHS) in 2000 and 2014. Methods: The paper estimates the logistic regression model, zero-inflated negative binomial model (ZINB), and negative binomial regression model (NB) to identify the most important determinants of antenatal health care utilization. Results: The findings indicate that the period 2000-2014 has experienced a significant increase in the use of antenatal health care services. The use of the public sector antenatal care services relative to that of the private sector has been decreasing over time. Moreover, wealth index, women's education and quality of health services play significant roles in increasing accessibility of antenatal health care services. On the other hand, women's empowerment has shown a positive effect in 2000 only. Conclusion: The study highlights the most vulnerable groups that are less likely to have access to antenatal health care services, mainly women who are less educated, poor and living in rural areas especially Upper Egypt. This certainly requires a more targeted health strategy with an equity lens.
\end{abstract}

\section{Keywords}

Antenatal Health Care Services, Binary and Count Data, Negative Binomial Regression, Determinants, Egypt 


\section{Introduction}

Complications resulting from pregnancy and childbirth are still the most important reasons of death and morbidity among women of reproductive age in developing countries more than any other single health problem [1]. Every day, about 830 women around the world die from causes related to pregnancy and delivery and the majority are concentrated in low-income countries. These deaths could have been circumvented through an effective and efficient antenatal health care system [2]. Early and regular antenatal health care by trained medical providers are very important in assessing the physical status of women during pregnancy [3]. A strategy that encourages universal access to antenatal health care will assist in decreasing maternal and neonatal mortality [4].

Egypt has started its health sector reform program since mid-2000s. Throughout these years, the program has continued to develop with varying degrees of success and failure. The main objective was to improve access and provide quality services at the primary level through a basic benefit package that included maternal services.

While much has been written on the socioeconomic and demographic determinants of antenatal health care utilization among women in Egypt [5] [6] [7] [8], comparatively little is known about the determinants of the frequency of antenatal care visits [9] [10]. Therefore, this study explores the prevalence of antenatal health care utilization in Egypt in 2000 and 2014. Additionally, this paper intends to investigate the determinants of utilization of antenatal care, the frequency of that use, and the timing of receiving antenatal care in 2000 and 2014 using the logistic regression, negative binomial regression, and zero-inflated negative binomial regression. Finally, the current study updates a previous article by Zaky et al. [10] using the most recent dataset available in Egypt in 2014. The previous study looked at a shorter period of time from 2000 to 2008. The availability of the most recent data in Egypt in 2014 allows for a longer period of follow-up from 2000 to 2014 as well as it is the first available national survey after the two revolutions that Egypt experienced earlier in this decade. Moreover, the previous article [10] used the number of antenatal care visits to represent antenatal care utilization but this study adds other new variables such as timing of receiving antenatal care and place of antenatal care. Most of the previous studies in Egypt used logistic regression model [6] [7] [8] but our study uses negative binomial regression, and zero-inflated negative binomial regression, in addition to logistic regression.

\section{Data and Methods}

\subsection{Data}

The study uses data derived from Egypt Demographic and Health Surveys conducted in 2000 and 2014 (EDHS 2000 and 2014) where EDHS 2014 is the latest national health survey in Egypt. The samples of the EDHSs are national multi-stage random samples of ever-married women. The sub-samples used in the 
study include married women aged 15 - 49 years whose last birth was during the five-year period preceding the surveys since antenatal health care data was solely collected from this group of women. The sub-samples of women amounted to 8001 and 11,495 women in 2000 and 2014 respectively.

Table 1 presents the percentage distribution of women whose last birth was in the five-year period before the survey according to some of their background characteristics. The majority of women (60 and 68 percent) are living in rural areas at the time of the survey (in 2000 and 2014 respectively). Looking at the age distribution in Table 1, more than half of those women are under age 30. On the other hand, women were fairly evenly distributed across the wealth quintiles at the time of the survey.

Regarding the educational level of women and their husbands, there is a rise in level of the education. About 36 and 43 percent of women and their husbands have completed at least the secondary level in 2000, while these percentages increased to 59 and 61 percent in 2014. Data of Table 1 show that 13 and 11 percent of ever married women were working for cash in 2000 and 2014 respectively.

\subsection{Methods}

To identify the most important determinants of antenatal health care utilization, the logistic regression model is used. The study uses the following three binary outcome variables to represent the dependent variables in the models: 1) Receiving antenatal care (whether or not the woman visited at least one antenatal care during the last pregnancy); 2) Timing of receiving antenatal care (whether or not the woman received first antenatal care visit during the first trimester); 3) Place of antenatal care (whether or not the woman received antenatal care from a public provider).

Moreover, the paper assesses the determinants of number of antenatal care visits in 2000 and 2014. Since the dependent variable, number of antenatal care visits, is measured as count data, the Poisson or Negative Binomial regression is used. The zero-inflated count models are also used to account for the large number of observations whose value is zero, According to Lambert, these models are two-step models [11] [12]. Owing to the large proportion of zeros due to women who did not receive antenatal health care in 2000 (almost 45 percent), the zero-inflated negative binomial model (ZINB) is used. In 2014, this percentage decreases to only 10 percent and the negative binomial regression (NB) is used.

From the previous review of the literature in Egypt, it can be concluded that there are some factors such as wealth index, educational level, place of residence, women's age, women's empowerment, availability and quality of health services influenced antenatal health care utilization [6] [7] [8] [9] [10]. The explanatory variables include wealth index, women's age, work status, women's education, partner's education, place of residence, region, exposure to media (newspaper, $\mathrm{TV}$, and radio), women's empowerment, and availability and quality of health 
Table 1. Distribution of women whose last birth was during the five-year period preceding the survey according to women's background characteristics (2000-2014).

\begin{tabular}{|c|c|c|c|c|}
\hline \multirow{2}{*}{ Items } & \multicolumn{2}{|c|}{2000} & \multicolumn{2}{|c|}{2014} \\
\hline & $\%$ & $\mathrm{~N}$ & $\%$ & $\mathrm{~N}$ \\
\hline \multicolumn{5}{|l|}{ Place of residence } \\
\hline Urban & 40.5 & 3395 & 31.8 & 3625 \\
\hline Rural & 59.5 & 4606 & 68.2 & 7766 \\
\hline \multicolumn{5}{|l|}{ Region } \\
\hline Urban governorates & 16.8 & 1382 & 10.8 & 1231 \\
\hline Urban lower Egypt & 11.6 & 858 & 9.4 & 1071 \\
\hline Rural lower Egypt & 30.9 & 2151 & 39.0 & 4442 \\
\hline Urban upper Egypt & 11.1 & 828 & 11.1 & 1263 \\
\hline Rural upper Egypt & 28 & 2241 & 28.8 & 3277 \\
\hline Frontier governorates & 1.5 & 541 & 0.9 & 107 \\
\hline \multicolumn{5}{|l|}{ Current age } \\
\hline $15-19$ & 3.8 & 285 & 3.1 & 348 \\
\hline $20-24$ & 22.1 & 1732 & 21.3 & 2423 \\
\hline $25-29$ & 29.7 & 2363 & 33.9 & 3866 \\
\hline $30-34$ & 22.5 & 1803 & 24.2 & 2751 \\
\hline $35-39$ & 14.7 & 1215 & 12.6 & 1438 \\
\hline $40-44$ & 5.5 & 469 & 4.2 & 481 \\
\hline $45-49$ & 1.6 & 134 & 0.7 & 84 \\
\hline \multicolumn{5}{|l|}{ Educational attainment } \\
\hline No education & 38.7 & 3084 & 17.8 & 2027 \\
\hline Incomplete primary & 11.5 & 907 & 4.9 & 554 \\
\hline Complete primary & 4.2 & 325 & 3.9 & 439 \\
\hline Incomplete secondary & 9.8 & 807 & 14.4 & 1637 \\
\hline Complete secondary & 27.1 & 2205 & 43.0 & 4902 \\
\hline Higher & 8.5 & 673 & 16.1 & 1832 \\
\hline \multicolumn{5}{|l|}{ Work status } \\
\hline Not working for cash & 86.9 & 6912 & 88.6 & 10,090 \\
\hline Working for cash & 13.1 & 1089 & 11.4 & 1301 \\
\hline \multicolumn{5}{|l|}{ Reading newspaper } \\
\hline No & 60.9 & 4813 & 86.1 & 9806 \\
\hline Yes & 38.9 & 3179 & 13.9 & 1585 \\
\hline \multicolumn{5}{|l|}{ Watching $T V$} \\
\hline No & 5.7 & 533 & 1.5 & 169 \\
\hline Yes & 94.3 & 7468 & 98.5 & 11221 \\
\hline \multicolumn{5}{|l|}{ Listening to radio } \\
\hline No & 17.7 & 1487 & 79.1 & 9005 \\
\hline Yes & 82.3 & 6512 & 20.9 & 2386 \\
\hline
\end{tabular}




\section{Continued}

\begin{tabular}{ccccc}
\hline Wealth index & & & & \\
Poorest & 19.5 & 1600 & 17.2 & 1959 \\
Poorer & 19.1 & 1450 & 19.3 & 2201 \\
Middle & 20.3 & 1634 & 24.9 & 2831 \\
Richer & 21.7 & 1715 & 21.5 & 2446 \\
Richest & 19.3 & 1602 & 17.2 & 1954 \\
Husband s education & & & & \\
No education & 24.4 & 1948 & 12.9 & 1466 \\
Incomplete primary & 14.6 & 1162 & 7.7 & 878 \\
Complete primary & 6.3 & 501 & 5.7 & 649 \\
Incomplete secondary & 11.7 & 931 & 12.4 & 1414 \\
Complete secondary & 29.4 & 2391 & 44.3 & 5044 \\
Higher & 13.5 & 1068 & 17.0 & 1940 \\
Total & 100 & 8001 & 100 & 11391 \\
\hline
\end{tabular}

services. The last three variables, women's empowerment, availability and quality of health services are not readily available. Following on Zaky et al., this study constructs factors to express each one of them and they are created by Exploratory Factor Analysis technique (EFA) from several variables [10]. Appendices include the rotated factor loading of the variables creating the factors.

\section{Results}

Changes in antenatal health care indicators between EDHS 2000 and EDHS 2014 are summarized in Table 2. It shows that there are substantial gains in antenatal health care coverage. The results reveal that the percentage of women who had any antenatal health care, regular antenatal health care, and their first checkup in the first trimester of pregnancy increased from 2000 to 2014. The results show that women received regular antenatal care (4 visits or more) for 39 percent of last births in the five years period before the survey in 2000, compared to about 83 percent in 2014. Among women who received any antenatal care, more than three quarters (77 and 83 percent) started visits before the fourth month of pregnancy in 2000 and 2014 respectively.

According to Table 2, there is a significant decline in the proportion of receiving antenatal care from a public provider during the period 2000-2014, from 26 percent to 16 percent. This result confirms the dominance of the private sector services and its expansion during the same period.

The study estimates three logistic regression models to assess the main determinants of receiving ANC, the timing of antenatal care, and place of antenatal care and only the significant variables are shown in Table 3. It should be mentioned that each model of the three models is significant with a p-value less than 0.01 . 
Table 2. Antenatal health care indicators in 2000 and 2014.

\begin{tabular}{ccccc}
\hline Indicator & 2000 & 2014 & Change & Difference \\
\hline $\begin{array}{c}\text { Women receiving any ANC } \\
\text { Women receiving regular ANC }\end{array}$ & 55.8 & 89.8 & $34(+)$ & Sig. \\
$\begin{array}{c}\text { Women receiving first ANC visit } \\
\text { within the first trimester of pregnancy }\end{array}$ & 77.3 & 83.3 & $6(+)$ & Sig. \\
$\begin{array}{c}\text { Women receiving ANC from a public provider } \\
\text { Wor. }\end{array}$ & 25.6 & 16 & $9.6(-)$ & Sig. \\
\hline
\end{tabular}

(+) increased; (-) decreased.

Table 3. Results of the logistic regression (odds ratio) for examining the determinants of antenatal health care (2000-2014).

\begin{tabular}{|c|c|c|c|c|c|c|}
\hline \multirow{2}{*}{ Variables } & \multicolumn{2}{|c|}{ Receiving ANC } & \multicolumn{2}{|c|}{ Timing of ANC } & \multicolumn{2}{|c|}{ Place of ANC } \\
\hline & 2000 & 2014 & 2000 & 2014 & 2000 & 2014 \\
\hline \multicolumn{7}{|l|}{ Women's age } \\
\hline \multicolumn{7}{|l|}{$15-24$ (ref.) } \\
\hline $25-39$ & $0.88^{* * *}$ & 1.21 & $0.78^{*}$ & 0.98 & 1.05 & 0.99 \\
\hline $40-49$ & $0.77^{\star * *}$ & 0.56 & 0.82 & $0.65^{\star}$ & 0.91 & 0.93 \\
\hline \multicolumn{7}{|l|}{ Terminated pregnancy } \\
\hline \multicolumn{7}{|l|}{ No (ref.) } \\
\hline Yes & $1.29^{*}$ & 1.28 & $1.17^{\star * *}$ & $1.18^{\star \star}$ & $0.77^{\star}$ & $0.77^{\star}$ \\
\hline \multicolumn{7}{|l|}{ Educational attainment } \\
\hline \multicolumn{7}{|l|}{ No education (ref.) } \\
\hline Incomplete primary & 0.92 & 0.89 & 0.99 & 1.01 & 0.99 & $0.69^{*}$ \\
\hline Complete primary & 0.96 & 0.98 & 0.86 & 0.83 & 0.87 & $0.64^{*}$ \\
\hline Incomplete secondary & 1.05 & 2.19 & 0.99 & 1.15 & 0.82 & $0.68^{\star}$ \\
\hline Complete secondary & 0.98 & 1.56 & $1.32^{\star * *}$ & 1.13 & $0.75^{\star * *}$ & $0.59^{\star}$ \\
\hline Higher & $1.84^{*}$ & 6.83 & $1.5^{\star * *}$ & $1.38^{\star *}$ & $0.41^{*}$ & $0.44^{*}$ \\
\hline \multicolumn{7}{|l|}{ Husband s Education } \\
\hline \multicolumn{7}{|l|}{ No education (ref.) } \\
\hline Incomplete primary & 1.1 & 0.60 & 1.02 & 1.19 & 1.03 & 1.17 \\
\hline Complete primary & 0.97 & 10.58 & 0.81 & $1.42^{\star}$ & $1.53^{*}$ & 0.82 \\
\hline Incomplete secondary & 0.97 & 0.85 & 1.02 & 1.09 & 0.97 & 0.99 \\
\hline Complete secondary & 1.06 & 0.92 & 1.002 & $1.5^{*}$ & 0.85 & $0.74^{*}$ \\
\hline Higher & $1.39^{* *}$ & 0.77 & 1.13 & $1.39^{\star}$ & $0.62^{*}$ & $0.58^{*}$ \\
\hline \multicolumn{7}{|l|}{ Region } \\
\hline \multicolumn{7}{|l|}{ Urban governorates (ref.) } \\
\hline Urban lower Egypt & 0.88 & 0.35 & $0.66^{*}$ & 0.80 & $0.44^{*}$ & $0.64^{*}$ \\
\hline Rural lower Egypt & 0.61 & 0.35 & 0.90 & 0.64 & $0.25^{\star *}$ & $0.31^{* *}$ \\
\hline Urban upper Egypt & $0.63^{*}$ & 0.49 & 0.89 & 0.95 & $0.53^{*}$ & $0.65^{\star}$ \\
\hline Rural upper Egypt & 0.49 & 0.24 & 1.21 & 0.62 & $0.24^{*}$ & 0.47 \\
\hline Frontier governorates & $0.44^{* *}$ & 0.90 & 1.16 & 1.61 & 0.74 & 0.86 \\
\hline
\end{tabular}




\section{Continued}

\begin{tabular}{|c|c|c|c|c|c|c|}
\hline Wealth index & & & & & & \\
\hline \multicolumn{7}{|l|}{ Poorest (ref.) } \\
\hline Poorer & 1.17 & $1.80^{* * *}$ & 1.06 & 0.998 & 0.92 & $1.21^{\star \star}$ \\
\hline Middle & $1.41^{\star}$ & $3.31^{\star}$ & $1.42^{* *}$ & $1.22^{\star *}$ & $0.67^{*}$ & $1.21^{\star *}$ \\
\hline Richer & $1.92^{\star}$ & $2.90^{\star \star}$ & $1.71^{\star}$ & $1.99^{\star}$ & $0.59^{*}$ & 1.15 \\
\hline Richest & $2.44^{\star}$ & $4.51^{\star}$ & $2.5^{\star}$ & $2.96^{\star}$ & $0.22^{*}$ & $0.63^{*}$ \\
\hline \multicolumn{7}{|l|}{ Listening } \\
\hline \multicolumn{7}{|l|}{ No (ref.) } \\
\hline Yes & 0.89 & 1.64 & $1.37^{\star}$ & $1.16^{* *}$ & 0.93 & 1.10 \\
\hline \multicolumn{7}{|l|}{ Reading } \\
\hline \multicolumn{7}{|l|}{ No (ref.) } \\
\hline Yes & $1.24^{* *}$ & 1.16 & 0.94 & 1.07 & 0.99 & $1.28^{*}$ \\
\hline Content of medical care & $2.75^{\star}$ & $1.72^{\star}$ & $1.13^{*}$ & $1.27^{\star}$ & $1.33^{*}$ & $1.16^{*}$ \\
\hline Treatment with complications & $2.14^{\star}$ & $1.66^{*}$ & 1.04 & $1.31^{\star}$ & 0.94 & 0.90 \\
\hline Making daily decisions & 0.99 & 0.54 & $1.11^{*}$ & 1.02 & $0.85^{*}$ & 1.00 \\
\hline Freedom of movement & $1.11^{\star}$ & 0.49 & 1.06 & 0.995 & 1.03 & 1.05 \\
\hline
\end{tabular}

Source: Calculated by the authors using EDHS, 2000 and $2014 .{ }^{*}$ Significant at level $1 \%$; ${ }^{* *}$ Significant at level $5 \%$; ${ }^{* *}$ Significant at level $10 \%$.

Regarding receiving antenatal care, the final model predicts correctly 77 and 89 percent of the cases in 2000 and 2014 respectively. The results show that women in the age groups 25 - 39 years and 40 - 49 years are less likely than those younger women aged 15 - 24 to receive any antenatal care only in 2000. This may be due to their experience. Moreover, women in the richest quintile are two and five times more likely to receive any antenatal care than women in the poorest quintile in 2000 and 2014 respectively. Additionally, indicators of quality of health services have a high significant and positive impact on the probability that women receive any antenatal care in 2000 and 2014.

The analysis of the EDHS 2000 analysis showed some different results than that of 2014. According to Table 3 and the analysis of the 2000 dataset, only freedom of movement from women's empowerment has a positive effect on antenatal care use. Additionally, women from rural Upper Egypt or Frontier governorates are less likely to receive any antenatal care than women from urban governorates. Moreover, women with a university education or higher are more likely to receive any antenatal care than women who have never attended school. These findings are not evident in 2014. This may be because most women receive ANC according to the 2014 analysis, and there is no significant difference between regions, or between educated or non-educated women.

With respect to the timing of antenatal care, it should be mentioned that the final model predicts correctly 77 and 83 percent of the cases in 2000 and 2014 respectively. The results reveal that older mothers are less likely to receive first antenatal care visit during the first trimester than younger mothers in 2000 and 
2014. As shown in Table 3, women in the richest quintile are two and three times more likely to receive first antenatal care visit during the first trimester than women in the poorest quintile in 2000 and 2014 respectively. Additionally, women whose their husbands have a university education or higher are more likely to receive first antenatal care visit during the first trimester than women whose their husbands have never attended school only in 2014.

Table 3 indicates that experiencing a terminated pregnancy does increase the likelihood to receive their first antenatal care visit during the first trimester in both 2000 and 2014. Quality of health services has positive impact on the likelihood that women receive their first antenatal care visit during the first trimester in 2000 and 2014. At the same time, making daily decisions of women's empowerment has a positive effect on receiving first antenatal care visit during the first trimester in 2000 only.

Turning to the place of antenatal care, it should be mentioned that the final model predicts correctly 76 and 84 percent of the cases in 2000 and 2014 respectively. The results indicate that the exposure to a terminated pregnancy decreases the probability of receiving antenatal care from a public provider in 2000 and 2014. Additionally, women from Lower or Upper Egypt are less likely to receive antenatal care from a public provider than women from urban governorates in 2000 and 2014.

According to Table 3, women with a university education or higher are less likely to receive antenatal care from a public provider than women have never attended school in 2000 and 2014. Additionally, women whose husbands have a university education or higher are less likely to receive antenatal care from a public provider than women whose husbands have never attended school in 2000 and 2014. Moreover, women in the richest quintile are less likely to receive antenatal care from a public provider than women in the poorest quintile in 2000 and 2014. As shown in Table 3, only making daily decisions from indicators of women's empowerment has a negative impact on receiving antenatal care from a public provider only in 2000 .

The study estimates the zero-inflated Negative Binomial (ZINB) model and the Negative Binomial (NB) model to examine the main determinants for the number of ANC visits, where only the significant variables of the two models are shown in Table 4. The coefficients are defined as the expected number of antenatal care visits changes with the change of exponential (coefficient) for each unit in the corresponding independent variable controlling for all other variables [13]. As shown in Table 4, women's education is associated with the number of antenatal care visits. The expected number of antenatal care visits for women with a university education or higher is 1.14 and 1.16 times the expected number of antenatal care visits for women with no education in both 2000 and 2014 respectively. With regard to wealth index, the findings indicate that it has a significant positive impact on the number of antenatal care visits in 2000 and 2014. The expected number of antenatal care visits for women in the richest quintile is almost 20 percent higher than that of the poorest quintile in both 2000 and 2014. 
Table 4. Results of ZINB and NB regression for examining the determinants of number of antenatal visits (2000-2014).

\begin{tabular}{|c|c|c|c|c|}
\hline \multirow{2}{*}{ Variables } & \multicolumn{2}{|c|}{ ZINB (2000) } & \multicolumn{2}{|c|}{ NB (2014) } \\
\hline & Coefficient & Exp (coeff.) & Coefficient & Exp (coeff.) \\
\hline Women's age & -0.00146 & 0.999 & $-0.00236^{* *}$ & 0.998 \\
\hline \multicolumn{5}{|l|}{ Terminated pregnancy } \\
\hline \multicolumn{5}{|l|}{ No (ref.) } \\
\hline Yes & $0.09872^{\star}$ & 1.10 & $0.07006^{\star}$ & 1.073 \\
\hline \multicolumn{5}{|l|}{ Educational attainment } \\
\hline \multicolumn{5}{|l|}{ No education (ref.) } \\
\hline Incomplete primary & 0.02018 & 1.02 & 0.03502 & 1.036 \\
\hline Complete primary & $0.14607^{\star *}$ & 1.16 & $0.05436^{* * *}$ & 1.056 \\
\hline Incomplete secondary & $0.15080^{*}$ & 1.16 & $0.08644^{*}$ & 1.090 \\
\hline Complete secondary & $0.11610^{*}$ & 1.12 & $0.10308^{*}$ & 1.109 \\
\hline Higher & $0.12699^{* *}$ & 1.14 & $0.14841^{\star}$ & 1.160 \\
\hline \multicolumn{5}{|l|}{ Partner's s education } \\
\hline \multicolumn{5}{|l|}{ No education (ref.) } \\
\hline Incomplete primary & 0.02678 & 1.03 & -0.01031 & 0.990 \\
\hline Complete primary & $-0.11883^{\star *}$ & 0.89 & 0.01319 & 1.013 \\
\hline Incomplete secondary & -0.03093 & 0.97 & 0.01437 & 1.014 \\
\hline Complete secondary & -0.02843 & 0.97 & 0.00297 & 1.003 \\
\hline Higher & -0.03666 & 0.96 & 0.00367 & 1.004 \\
\hline \multicolumn{5}{|l|}{ Relationship between spouses } \\
\hline No (ref.) & - & & & \\
\hline Yes & $0.03788^{* * *}$ & 0.96 & 0.00474 & 1.005 \\
\hline \multicolumn{5}{|l|}{ Region } \\
\hline \multicolumn{5}{|l|}{ Urban governorates (ref.) } \\
\hline Urban lower Egypt & 0.02883 & 1.03 & $0.11385^{\star}$ & 1.121 \\
\hline Rural lower Egypt & -0.03968 & 0.96 & $0.10566^{\star *}$ & 1.111 \\
\hline Urban upper Egypt & 0.012288 & 1.01 & $0.10314^{*}$ & 1.109 \\
\hline Rural upper Egypt & $-0.23841^{*}$ & 0.79 & $0.08366^{* * *}$ & 1.087 \\
\hline Frontier governorates & $-0.32638^{\star \star}$ & 0.72 & -0.02571 & 0.975 \\
\hline \multicolumn{5}{|l|}{ Wealth index } \\
\hline \multicolumn{5}{|l|}{ Poorest (ref.) } \\
\hline Poorer & -0.02793 & 0.97 & 0.02091 & 1.02 \\
\hline Middle & $0.17056^{\star}$ & 1.19 & $0.10160^{*}$ & 1.11 \\
\hline Richer & $0.19834^{*}$ & 1.22 & $0.17841^{*}$ & 1.20 \\
\hline Richest & $0.34406^{*}$ & 1.41 & $0.26005^{*}$ & 1.30 \\
\hline Content of antenatal care & $0.17758^{\star}$ & 1.19 & $0.06731^{\star}$ & 1.070 \\
\hline The signs of pregnancy complications & $0.13748^{*}$ & 1.15 & $0.05687^{*}$ & 1.059 \\
\hline Freedom of movement & $0.03785^{\star}$ & 1.04 & 0.00869 & 1.009 \\
\hline Vuong test & \multicolumn{2}{|c|}{$27.22 *$} & & \\
\hline Likelihood-ratio test & \multicolumn{2}{|c|}{$3570.72 *$} & \multicolumn{2}{|c|}{$3876.44^{*}$} \\
\hline
\end{tabular}

Source: Calculated by the authors using EDHS, 2000 and 2014. ${ }^{*}$ Significant at level $1 \%$; ${ }^{*}$ Significant at level $5 \%$; $* *$ Significant at level $10 \%$. 
The results of the model reveal that age has a negative significant impact on the number of antenatal care visits in 2014. As shown in Table 4, the expected number of antenatal care visits decreases by almost one visit if the current age of woman increases by one year. On the other hand, the current age of women does not affect the number of ANC visits in 2000. Moreover, the findings of this study show that the exposure to a terminated pregnancy enhances the number of antenatal care visits in 2000 and 2014.

As indicated in Table 4, the quality of health services is positively related to the number of antenatal care visits in both 2000 and 2014. Similarly, the results show that the freedom of movement has a positive impact on the number of antenatal care visits in 2000. Individually increasing the quality of health services by one unit or the level of freedom of movement by one unit will increase the expected number of antenatal care visits by almost one visit.

As can be seen from Table 4, the variable region has a significant impact on the number of antenatal care visits. The expected numbers of ANC visits for women from Lower or Upper Egypt are more than the expected number of ANC visits for women from urban governorates in 2014, while the expected number of ANC visits for women from rural Upper Egypt is less than the expected number of ANC visits for women from urban governorates in 2000. This may be due to the availability of female health workers who may visit women and promotes the awareness of antenatal health care use.

According to Vuong test [13], the zero-inflated negative binomial is a better fit than the standard negative binomial in 2000. A significant likelihood ratio test for alpha equals zero shows that the negative binomial model is a better approximation than the Poisson model in 2000 and 2014 and that the data is over-dispersed.

\section{Discussion}

It can be concluded that quality of health services has a positive impact on receiving antenatal health care services in 2000 and 2014. These findings agree with the literature in other developing countries such as India and confirm similar results from Egypt which indicated that the higher the level of quality of health services, the higher the level of antenatal health care services utilization [10] [14].

The results indicate that women's empowerment is positively associated with the use of antenatal health care services in 2000 only. These findings agree with the literature in Indonesia, India, and Bangladesh which showed that the higher the level of women's empowerment, the higher the level of antenatal health utilization is [15] [16] [17]. Moreover, the increase of wife's share of household assets was associated with more antenatal health use [15].

Consistent with previous findings [6] [7] [8] [10] [16] [18] [19] [20] [21], wealth index plays an important role in raising the level of antenatal health services utilization in 2000 and 2014. The findings show that women from the rich- 
est regions are more likely to receive antenatal health than those from the poorest regions. This may be due to distance, maldistribution of road and health infrastructure, limited access to information and strong beliefs towards traditional values in the poorest regions [22]. Moreover, poor households are unwilling to spend their household income on preventive care for women [23]. Additionally, it can be concluded that place of ANC service varies by wealth index. This result agrees with the literature in Bangladesh which showed that the poorest women are more likely to receive antenatal care from a public provider than the richest women [24].

It can be noticed that age of women is one of the important determinants of antenatal health care services utilization. This finding is supported by a study in India; it is proved that the older women are less likely to receive antenatal health care services than younger women [25].

The results show that the probability of using antenatal health care services is strongly influenced by the education of both wife and husband. These results agree with the general findings of earlier studies [6] [7] [8] [10] [19] [20] [22] [26] [27], which showed that the higher the level of education, the higher the level of woman's awareness to use antenatal health services. Increasing woman's awareness of antenatal care utilization could affect her health care decision-making where lack of the woman's awareness of pregnancy complications in Indonesia was associated with underutilization of antenatal health care [28].

\section{Conclusions}

This study attempts to identify the most important determinants of antenatal health care services utilization by using the logistic regression model, zero-inflated negative binomial model (ZINB), and negative binomial regression (NB) during the period 2000-2014. To achieve the objectives of this paper, factor analysis technique is used to construct indicators of women's empowerment, availability and quality of health services. The findings show that there has been a sharp rise in the utilization of antenatal health care services from 2000 to 2014. Additionally, the likelihood of preferring the public sector relative to private sector for receiving antenatal care has been decreasing over time.

Quality of health services proves to be among the important determinants of antenatal health utilization. For that reason, it is recommended to emphasize the concept of quality of health services in any future health strategy. Moreover, further research is needed to investigate women satisfaction towards antenatal health services and the obstacles encountered during use to upgrade the quality of services.

One of the major findings of the study is that wealth index is considered to be the most important determinant of antenatal health care utilization. Therefore, more governmental efforts should be made to target poor households and to develop women's economic status and increase their awareness towards antenatal health care utilization especially in areas with degraded health services and/or those living in poverty. Additionally, the association between women's empo- 
werment and antenatal health services utilization suggests that women's empowerment needs to be considered as an important determinant for the higher utilization of antenatal health care services in Egypt.

This study has found that the educational levels of both the wife and the husband are among the important determinants of antenatal health care services utilizations. In addition, women residing in Upper Egypt are less likely to receive antenatal health services compared to women from urban governorates. Therefore, it is advisable to have a targeted health promotion campaign about antenatal health care in the less privileged areas.

Future research may examine whether antenatal health care utilization, availability and quality of health services are simultaneously determined or not in Egypt. Additionally, further research may investigate the factors determining the utilization of maternal health care services (antenatal care, delivery care, and postnatal care), which is needed using more refined and restructured measures for women's empowerment, availability and quality of health services. Moreover, it is important to target women who do not use antenatal health services to assess their reasons for not receiving antenatal health care services.

\section{Conflicts of Interest}

The authors declare no conflicts of interest regarding the publication of this paper.

\section{References}

[1] World Health Organization (2005) Make Every Mother and Child Count. WHO, Geneva.

[2] World Health Organization (2016) Media Center: Maternal Mortality. WHO, Geneva. http://www.who.int/mediacentre/factsheets/fs348/en/

[3] El-Zanaty, F. and Way, A.A. (2001) Egypt Demographic and Health Survey 2000. Ministry of Health and Population, National Population Council, and Macro International Inc., Cairo.

[4] World Health Organization (2014) WHO Recommendations on Postnatal Care of the Mother and Newborn 2013. WHO, Geneva.

[5] Faiad, M. (2000) Maternal and Child Health Care in Egypt: A Demographic Perspective. Population and Development Research Monograph, Series No. 7, Cairo Demographic Center, Cairo.

[6] Mohamed, M.A. (2003) Some Aspects of Safe Motherhood in Egypt. M.Sc. Thesis, Cairo Demographic Center, Cairo.

[7] Mostafa, A.A. (2003) Factors Affecting Utilization of Maternal Health Care Services in Egypt 2003. Population and Development Monograph, Series No. 34, Cairo Demographic Center, Cairo.

[8] Ahmed, S.M. (2005) Causes and Consequences of Maternal Health in Egypt 2000. M.Sc. Thesis, Cairo Demographic Center, Cairo.

[9] Hussein, M.A. (2009) Impact of Women's Empowerment on The Antenatal Health Care Utilization. M.Sc. Thesis, Faculty of Economics and Political Science, Cairo University, Cairo. 
[10] Zaky, H.H., Armanious, D.M. and Hussein, M.A. (2015) Impact of the Changes in Women's Characteristics over Time on Antenatal Health Care Utilization in Egypt (2000-2008). Open Journal of Obstetrics and Gynecology, 5, 542-552. https://doi.org/10.4236/ojog.2015.510078

[11] Lambert, D. (1992) Zero-Inflated Poisson Regression, with an Application to Defects in Manufacturing. Technometrics, 34, 1-14. https://doi.org/10.2307/1269547

[12] Cameron, A.C. and Trivedi, P.K. (2005) Micro-Econometrics: Methods and Applications. Cambridge University Press, New York.

[13] Scott Long, J. and Freese, J. (2006) Regression Models for Categorical Dependent Variables Using Stata. 2nd Edition, Stata Press, College Station, TX.

[14] Rani, M., Bonu, S. and Harvey, S. (2007) Differentials in the Quality of Antenatal Care in India. International Journal for Quality in Health Care, 20, 62-71. https://doi.org/10.1093/intqhc/mzm052

[15] Beegle, K., Frankenberg, E. and Thomas, D. (2001) Bargaining Power within Couples and Use of Prenatal and Delivery Care in Indonesia. Studies in Family Planning, 32, 130-146. https://doi.org/10.1111/j.1728-4465.2001.00130.x

[16] Bloom, S.S., Wypij, D. and Gupta, M.D. (2001) Dimensions of Women's Autonomy and the Influence on Maternal Health Care Utilization in a North Indian City. Demography, 38, 67-78. https://doi.org/10.1353/dem.2001.0001

[17] Haque, S.E., Rahman, M., Mostofa, M.G. and Zahan, M.S. (2012) Reproductive Health Care Utilization among Young Mothers in Bangladesh: Does Autonomy Matter. Women's Health Issues, 22, 171-180. https://doi.org/10.1016/j.whi.2011.08.004

[18] Doku, D., Neupane, S., and Doku, P.N. (2012) Factors Associated with Reproductive Health Care Utilization among Ghanaian Women. BMC International Health and Human Rights, 12, 29. https://doi.org/10.1186/1472-698X-12-29

[19] Gage, A. (2007) Barriers to the Utilization of Maternal Health Care in Rural Mali. Social Science and Medicine, 65, 1666-1682. https://doi.org/10.1016/j.socscimed.2007.06.001

[20] Sepehri, A., Sarma, S., Simpson, W. and Moshiri, S. (2008) How Important Are Individual, Household and Commune Characteristics in Explaining Utilization of Maternal Health Services in Vietnam. Social Science and Medicine, 67, 1009-1017. https://doi.org/10.1016/j.socscimed.2008.06.005

[21] Singh, A., Mukherjee, S. and Chandra, R. (2012) Inter-District Variation in Socio-Economic Inequalities in Maternal Healthcare Utilization in Rural Assam, 2007-2008. Journal of North East India Studies, 2, 94-103.

[22] Pebley, A., Goldman, N. and Rodriguez, G. (1996) Prenatal and Delivery Care and Childhood Immunization in Guatemala: Do Family and Community Matter. Demography, 33, 231-247. https://doi.org/10.2307/2061874

[23] Lule, E., Ramana, G.N.V., Oomman, N., Joanne, E., Huntington, D. and Rosen, J.E. (2005) Achieving the Millennium Development Goal of Improving Maternal Health: Determinants, Interventions and Challenges. The International Bank for Reconstruction and Development, Washington DC.

[24] Uddin, M.S.G. and Kibria, M.G. (2014) Choice of Service Facility for Maternal Care and Its Proximate Correlates. Bangladesh Journal of Scientific Research, 27, 175-185. https://doi.org/10.3329/bjsr.v27i2.26235

[25] Sharma, V., Mohan, U., Das, V. and Awasthi, S. (2012) Utilization Pattern of Antenatal Care in Lucknow under National Rural Health Mission. Indian Journal of Community Health, 24, 32-36. 
[26] Alexandre, P.K., Saint-Jean, G., Crandall, L. and Fevrin, E. (2005) Prenatal Care Utilization in Rural and Urban Areas of Haiti. Revista Panamericana de Salud Pública, 18, 84-92. https://doi.org/10.1590/S1020-49892005000700002

[27] Kamiya, Y. (2011) Women's Autonomy and Reproductive Health Care Utilization: Empirical Evidence from Tajikistan. Health Policy, 102, 304-313. https://doi.org/10.1016/j.healthpol.2011.04.001

[28] Titaley, C.R., Dibley, M.J. and Roberts, C.L. (2010) Factors Associated with Underutilization of Antenatal Care Services in Indonesia: Results of Indonesia Demographic and Health Survey 2002/2003 and 2007. BMC Public Health, 10, 485-494. https://doi.org/10.1186/1471-2458-10-485 


\section{Appendix}

Table A1. Rotated factor loadings of women's empowerment, EDHS 2000 and 2014.

\begin{tabular}{|c|c|c|c|c|c|c|c|c|}
\hline \multirow{3}{*}{ Variables } & \multicolumn{8}{|c|}{ Factors } \\
\hline & \multicolumn{2}{|c|}{ First } & \multicolumn{2}{|c|}{ Second } & \multicolumn{2}{|c|}{ Third } & \multicolumn{2}{|c|}{ Fourth } \\
\hline & 2000 & 2014 & 2000 & 2014 & 2000 & 2014 & 2000 & 2014 \\
\hline Major household purchases & 0.735 & 0.801 & 0.013 & 0.038 & 0.095 & 0.052 & 0.117 & 0.043 \\
\hline Daily household purchases & 0.667 & - & 0.050 & - & 0.012 & - & 0.170 & - \\
\hline Her health care & 0.731 & 0.772 & 0.004 & 0.027 & 0.071 & 0.030 & 0.149 & 0.058 \\
\hline Visits her family or relatives & 0.682 & 0.746 & 0.045 & 0.020 & 0.072 & 0.057 & 0.107 & 0.116 \\
\hline How her husband's earnings is used & - & 0.756 & - & 0.031 & - & 0.045 & - & 0.037 \\
\hline Work status & 0.105 & 0.074 & 0.035 & 0.034 & 0.985 & 0.984 & 0.052 & 0.030 \\
\hline How her money is used & 0.111 & 0.080 & 0.031 & 0.034 & 0.985 & 0.984 & 0.047 & 0.032 \\
\hline Current contraceptive use & 0.038 & 0.042 & 0.992 & 0.989 & 0.032 & 0.031 & 0.046 & 0.032 \\
\hline Decision about contraceptive use & 0.037 & 0.053 & 0.992 & 0.989 & 0.033 & 0.036 & 0.057 & 0.035 \\
\hline Getting a permission to go to the doctor & 0.144 & 0.105 & 0.035 & 0.018 & 0.044 & 0.011 & 0.790 & 0.761 \\
\hline Going to the doctor alone & 0.076 & 0.062 & 0.050 & 0.035 & 0.037 & 0.061 & 0.775 & 0.769 \\
\hline
\end{tabular}

Table A2. Rotated factor loadings of quality of health services, EDHS 2000 and 2014.

\begin{tabular}{lcccc}
\hline \multirow{2}{*}{ Variables } & \multicolumn{4}{c}{ Factors } \\
\cline { 2 - 5 } & \multicolumn{3}{c}{ First } & \multicolumn{2}{c}{ Second } \\
\cline { 2 - 5 } & $\mathbf{2 0 0 0}$ & $\mathbf{2 0 1 4}$ & $\mathbf{2 0 0 0}$ & $\mathbf{2 0 1 4}$ \\
\hline Blood pressure measured & $\mathbf{0 . 8 2 4}$ & $\mathbf{0 . 6 5 9}$ & 0.190 & 0.036 \\
Blood sample taken & $\mathbf{0 . 8 8 7}$ & $\mathbf{0 . 8 1 9}$ & 0.152 & 0.210 \\
Urine sample taken & $\mathbf{0 . 8 8 6}$ & $\mathbf{0 . 8 2 5}$ & 0.149 & 0.196 \\
Weight & $\mathbf{0 . 7 9 5}$ & $\mathbf{0 . 6 4 8}$ & 0.110 & 0.037 \\
Told about the signs of pregnancy complications & 0.108 & 0.150 & $\mathbf{0 . 8 0 8}$ & $\mathbf{0 . 6 3 9}$ \\
Given any iron tablets or syrup & 0.170 & 0.001 & $\mathbf{0 . 7 6 6}$ & $\mathbf{0 . 8 0 7}$ \\
\hline
\end{tabular}

